\title{
Immunodominant T-cell epitopes of MOG reside in its transmembrane and cytoplasmic domains in EAE OPEN
}

Aparna Shetty, $\mathrm{PhD}$ *

Sheena G. Gupta, PhD*

Michel Varrin-Doyer,

$\mathrm{PhD}$

Martin S. Weber, MD

Thomas Prod'homme,

$\mathrm{PhD}$

Nicolas Molnarfi, PhD

Niannian Ji, PhD

Patricia A. Nelson, $\mathrm{PhD}$

Juan C. Patarroyo, BS

Ulf Schulze-Topphoff,

$\mathrm{PhD}$

Stephen E. Fogal, BS

Thomas Forsthuber, MD,

$\mathrm{PhD}$

Raymond A. Sobel, MD

Claude C.A. Bernard,

$\mathrm{PhD}$

Anthony J. Slavin, PhD

Scott S. Zamvil, MD,

$\mathrm{PhD}$, FAAN

Correspondence to

Dr. Zamvil:

zamvil@ucsf.neuroimmunol.org

See companion article

Supplemental data at Neurology.org/nn

\section{ABSTRACT}

Objective: Studies evaluating T-cell recognition of myelin oligodendrocyte glycoprotein (MOG) in multiple sclerosis (MS) and its model, experimental autoimmune encephalomyelitis (EAE), have focused mostly on its 117 amino acid (aa) extracellular domain, especially peptide (p) 35-55. We characterized T-cell responses to the entire 218 aa MOG sequence, including its transmembrane and cytoplasmic domains.

Methods: T-cell recognition in mice was examined using overlapping peptides and intact fulllength mouse MOG. EAE was evaluated by peptide immunization and by adoptive transfer of MOG epitope-specific T cells. Frequency of epitope-specific T cells was examined by ELISPOT.

Results: Three T-cell determinants of MOG were discovered in its transmembrane and cytoplasmic domains, p119-132, p181-195, and p186-200. Transmembrane MOG p119-132 induced clinical EAE, CNS inflammation, and demyelination as potently as p35-55 in C57BL/6 mice and other $\mathrm{H}-2^{\mathrm{b}}$ strains. p119-128 contained its minimal encephalitogenic epitope. p119-132 did not cause disease in EAE-susceptible non-H-2 ${ }^{\mathrm{b}}$ strains, including Biozzi, NOD, and PL/J. MOG p119-132specific T cells produced Th1 and Th17 cytokines and transferred EAE to wild-type recipient mice. After immunization with full-length MOG, a significantly higher frequency of MOG-reactive T cells responded to p119-132 than to p35-55, demonstrating that p119-132 is an immunodominant encephalitogenic epitope. MOG p181-195 did not cause EAE, and MOG p181-195-specific T cells could not transfer EAE into wild-type or highly susceptible T- and B-cell-deficient mice.

Conclusions: Transmembrane and cytoplasmic domains of MOG contain immunodominant T-cell epitopes in EAE. A CNS autoantigen can also contain nonpathogenic stimulatory T-cell epitopes. Recognition that a myelin antigen contains multiple encephalitogenic and nonencephalitogenic determinants may have implications for therapeutic development in MS. Neurol Neuroimmunol Neuroinflammation 2014;1:e22; doi: 10.1212/NXI.0000000000000022

\section{GLOSSARY}

$\mathbf{a a}=$ amino acid(s); APC = antigen-presenting cell; EAE = experimental autoimmune encephalomyelitis; IFN = interferon; $\mathbf{I g}=$ immunoglobulin; IL = interleukin; $\mathbf{M H C}=$ major histocompatibility complex; $\mathbf{M O G}$ = myelin oligodendrocyte glycoprotein; MS = multiple sclerosis; TCR $=$ T-cell receptor; $\mathbf{W T}=$ wild-type.

Myelin oligodendrocyte glycoprotein (MOG) is currently the most commonly studied CNS autoantigen in multiple sclerosis (MS) and experimental autoimmune encephalomyelitis (EAE). ${ }^{1-4}$ Most studies in EAE and MS, although not all, ${ }^{2,5-8}$ have focused primarily on T-cell recognition of the 117 amino acid (aa) N-terminal extracellular immunoglobulin (Ig) "variable-like" domain of MOG. ${ }^{9-12}$ However, native full-length MOG is 218 aa and contains transmembrane and

\footnotetext{
*These authors contributed equally.

From the Department of Neurology and Program in Immunology (A.S., S.G.G., M.V.-D., T.P., N.M., P.A.N., J.C.P., U.S.-T., S.S.Z.), University of California, San Francisco; Department of Neuropathology and Department of Neurology (M.S.W.), University Medical Center, Georg-August University, Göttingen, Germany; Department of Immunology (N.J., T.F.), University of Texas at San Antonio; Boehringer Ingelheim (S.E.F., A.J.S.), Ridgefield, CT; Department of Pathology (R.A.S.), Stanford University, Stanford, CA; and Multiple Sclerosis Research Group (C.C.A.B.), Australian Regenerative Medicine Institute, Monash University, Clayton, Victoria, Australia. S.G.G. is currently at the Institute for Immunity Transplantation and Infection, Stanford University, Stanford, CA. T.P. is currently at Momenta Pharmaceuticals, Cambridge, MA. N.M. is currently at the Division of Neurology, Department of Clinical Neurosciences, Geneva University Hospital and the Department of Pathology and Immunology, Geneva Faculty of Medicine, University Medical Center, Geneva, Switzerland. J.C.P. is currently at Pfizer, Inc., Cambridge, MA.

Go to Neurology.org/nn for full disclosures. Funding information and disclosures deemed relevant by the authors, if any, are provided at the end of the article. The Article Processing Charge was paid by the authors.

This is an open access article distributed under the terms of the Creative Commons Attribution-Noncommercial No Derivative 3.0 License, which permits downloading and sharing the work provided it is properly cited. The work cannot be changed in any way or used commercially.
} 
cytoplasmic domains. ${ }^{5}$ Native MOG requires processing by antigen-presenting cells (APCs) for its presentation to major histocompatibility complex (MHC) II-restricted encephalitogenic $\mathrm{CD}^{+}$MOG peptide (p) 35-55-specific $\mathrm{T}$ cells. ${ }^{6}$ Indeed, susceptibility to MOG-induced $\mathrm{EAE}$ is affected by APC expression of invariant chain (Ii) and H-2M (HLA-DM) molecules that participate in MHC II biosynthesis and endocytic processing, which can also influence $\mathrm{T}$-cell epitope selection. Based on those findings and because previous studies of T-cell reactivity did not evaluate intact full-length MOG, we questioned whether undiscovered pathogenic T-cell epitopes of processed native MOG may exist.

In 2011, we reported on our discovery of 3 novel MOG T-cell determinants in C57BL/6 mice: an encephalitogenic epitope, MOG p119-132, located within the transmembrane domain, and 2 determinants, p181-195 and p186-200, which reside within the cytoplasmic domain. ${ }^{13}$ In an accompanying report, we have examined T-cell responses to the corresponding MOG determinants in patients with MS and healthy controls. ${ }^{14}$ In this study, we define the phenotypic and pathologic characteristics of the $T$ cells that recognize those epitopes in mice. We have examined T-cell reactivity to individual peptides from a library of overlapping 15-mers and 20-mers spanning the aa sequence of full-length MOG, as well as to native MOG. MOG p119-132 induced potent clinical and histologic EAE. Upon recall to immunization with full-length MOG, a higher frequency of T cells responded to p119-132 than to p35-55, suggesting that p119-132 is an immunodominant encephalitogenic MOG determinant. Of interest, although immunization with MOG p181195 and p186-200 induced robust T-cell proliferative responses, neither of these peptides induced clinical or histologic EAE. T cells specific for MOG p186-200 were incapable of transferring clinical or histologic EAE to wild-type (WT) mice and rarely caused histologic disease in recipient RAG1-deficient $\left(\mathrm{RAG}^{-1-}\right)$ mice, indicating that this T-cell epitope is only weakly encephalitogenic. Furthermore, MOG p181-195-specific T cells were incapable of inducing clinical or histologic EAE in either WT or $\mathrm{RAG}^{-1-}$ mice.
Thus, not all T-cell epitopes of myelin (self) antigens are pathogenic.

METHODS Mice. Female 5-8-week-old C57BL/6, B10, 129Sv/J, B10.A, B10.PL, PL/J, SJL/J, BALB/c, (PL/J × SJL/J)F $F_{1}$, C57BL/6 OVA p257-264-specific T-cell receptor (TCR) transgenic (OT-1) and RAG1 ${ }^{-1-}$ mice were purchased from the Jackson Laboratories (Bar Harbor, ME); NOD/MrkTac were purchased from Taconic (Oxnard, CA). BiozziABH/RijHSd mice were purchased from Harlan Laboratories (Blackthorn, United Kingdom). C57BL/6 B cell ${ }^{-/-}$JHT mice (B6.129P2-Igh-Jtm1Cgn/J) were provided by Mark Shlomchik. ${ }^{15}$ C57BL/6 MOG $^{-/}$mice were provided by Hugh Reid. ${ }^{16}$

Peptides. Overlapping synthetic MOG peptides spanning the entire 218 aa sequence of mouse MOG and associated truncated peptides were synthesized by Genemed Synthesis (San Antonio, TX). Mouse peptides MOG p35-55 (MEVGWYRSPFSRVVHLYRNGK), MBP peptide Ac1-11 (Ac-ASQKRPSQRHG), PLP p139-151 (HCLGKWLGHPDKF), PLP p180-199 (WTTCQSIAFPSKTSAS IGSL), and OVA p257-264 (SIINFEKL) were purchased from AnaSpec (Fremont, CA). Mouse MOG p119-132 (FYWVNPGVLTLIAL), p119-130 (FYWVNPGVLTLI), p181-195 (TLFVIVPVLGPLVAL), and p186-200 (VPVLGPLV ALIICYN) were synthesized by Genemed Synthesis. Major peaks, analyzed by matrix-assisted laser desorption/ionization time of flight mass spectrometry and high-performance liquid chromatography, contained greater than $95 \%$ of the desired product.

Frequency analysis. Mice were immunized with either full-length or recombinant mouse MOG. After 12 days, lymph node cells were isolated and cultured for 12-14 days with the respective antigen used for immunization. Quantification was done upon restimulation using the Mouse IFN- $\gamma$ ELISPOT Ready-SET-Go! kit (eBioscience, San Diego, CA) according to instructions provided by the manufacturer. Ninety-six-well polyvinylidene fluoride membrane ELISPOT plates (Millipore, Billerica, MA) were coated overnight with interferon (IFN)- $\gamma$-specific capture antibodies. After blocking with complete medium, plates were washed and lymphocytes were plated at $1 \times 10^{4}$ cells/well with $2.5 \times 10^{5}$ irradiated splenocytes alone or with various antigens $(1-50 \mu \mathrm{g} / \mathrm{mL})$ and cultured for 24 hours in a $37^{\circ} \mathrm{C}, 5 \% \mathrm{CO}_{2}$ humidified incubator. Plates were washed and incubated overnight with the biotinylated anti-IFN- $\gamma$ detection antibodies. This plate-bound secondary antibody was visualized by adding avidin-horseradish peroxidase and 3-amino-9ethylcarbazole substrate (BD Biosciences, San Jose, CA). Image analysis of ELISPOT assays was performed on a Series 2 ImmunoSpot Image Analyzer using 4.0 software (Cellular Technology Limited, Shaker Heights, OH).

Statistics. T-cell proliferation data are presented as medians and means \pm SEM, respectively. For EAE clinical scores, significance between groups was examined by Mann-Whitney $U$ test. All other statistical comparisons between groups were performed with GraphPad Prism software using analysis of variance where $p<0.05$ was considered statistically significant.

Information on affinity purification of full-length MOG and rMOG 1-117, myelin isolation, lymphocyte isolation and proliferation, EAE induction and clinical evaluation, isolation of CNSinfiltrating mononuclear cells, flow cytometry analysis, cytokine ELISAs, and histopathology can be found in the e-Methods at Neurology.org/nn.

RESULTS Native MOG contains multiple T-cell determinants in C57BL/6 mice. Overlapping 15 and 
20 aa peptides spanning the entire 218 aa sequence of murine MOG were tested for their capability to elicit T-cell proliferative responses in C57BL/6 mice (table 1). In addition to p35-55, p111-130, p181-195, and p186-200 stimulated recall proliferative responses (figure e-1A). Following immunization with fulllength MOG, responses could be detected (stimulation index $>2.5$ ) for each of these peptides. The MOG 111-130 sequence contains aa residues from the distal extracellular and proximal transmembrane domains. $^{2}$ Immunization with rMOG 1-117 stimulated a recall response to p35-55 but not to 111-130 (figure 1A), indicating that the core of this novel T-cell determinant is located within the transmembrane region. Further, MOG 111-130 and 35-55 sequences are not homologous, and the proliferative responses induced by immunization with either p35-55 or p111-130 were not cross-reactive (figure e-1A). Residues 181-200 correspond to a hydrophobic sequence within the cytoplasmic domain that is thought to be associated with the cell

Table 1 Identification of immunogenic and encephalitogenic peptides of MOG

\begin{tabular}{|c|c|c|c|c|}
\hline \multicolumn{2}{|c|}{ MOG peptides } & \multicolumn{2}{|c|}{$\begin{array}{l}\text { Antigen for primary } \\
\text { immunization }\end{array}$} & \multirow{2}{*}{$\begin{array}{l}\mathrm{EAE} \\
\text { incidence }\end{array}$} \\
\hline Residues & Sequence & Peptide ${ }^{a}$ & rMOG 1-117a & \\
\hline p1-20 & GQFRVIGPRHPIRALVGDEA & - & & $0 / 10$ \\
\hline p11-30 & PIRALVGDEAELPCRISPGK & - & & $0 / 10$ \\
\hline p21-40 & ELPCRISPGKNATGMEVGWY & - & & $0 / 10$ \\
\hline p31-50 & NATGMEVGWYRSPFSRVVHL & + & + & $15 / 15$ \\
\hline p41-60 & RSPFSRVVHLYRNGKDQDAE & - & & $0 / 10$ \\
\hline p51-70 & YRNGKDQDAEQAPEYRERTE & - & & $0 / 10$ \\
\hline p61-80 & QAPEYRERTELLKETISEGK & - & & $0 / 10$ \\
\hline p71-90 & LLKETISEGKVTLRIQNVRF & - & & $0 / 10$ \\
\hline p81-100 & VTLRIQNVRFSDEGGYTCFF & - & & $0 / 10$ \\
\hline p91-110 & SDEGGYTCFFRDHSYQEEAA & - & & $0 / 10$ \\
\hline p101-120 & RDHSYQEEAAMELKVEDPFY & - & & $0 / 10$ \\
\hline p111-130 & MELKVEDPFYWVNPGVLTLI & + & - & $15 / 15$ \\
\hline p121-140 & WVNPGVLTLIALVPTILLQV & - & & $0 / 10$ \\
\hline p131-150 & ALVPTILLQVPVGLVFLFLQ & - & & $0 / 10$ \\
\hline p141-160 & VGLVFLFLQHRLRGKLRAE & - & & $0 / 10$ \\
\hline p151-170 & HRLRGKLRAEVENLHRTFDP & - & & $0 / 10$ \\
\hline p161-180 & VENLHRTFDPHFLRVPCWKI & - & & $0 / 10$ \\
\hline p171-190 & HFLRVPCWKITLFVIVPVLG & - & & $0 / 10$ \\
\hline p181-195 & TLFVIVPVLGPLVAL & + & - & $0 / 30$ \\
\hline p186-200 & VPVLGPLVALIICYN & + & - & $0 / 30$ \\
\hline p191-210 & PLVALIICYNWLHRRLAGQF & - & & $0 / 10$ \\
\hline p201-218 & WLHRRLAGQFLEELRNPF & - & & $0 / 10$ \\
\hline
\end{tabular}

Abbreviations: $\mathrm{EAE}=$ experimental autoimmune encephalomyelitis; MOG = myelin oligodendrocyte glycoprotein.

${ }^{a}$ A stimulation index $>2.5$ was considered positive. Each proliferation assay was performed on 4 mice. Results are representative of 3 independent experiments. membrane. ${ }^{17}$ Although overlapping, T cells primed to p181-195 or p186-200 responded only to the peptide used for immunization (figure e-1A). Thus, our results indicated that each of the 4 MOG peptides contained unique T-cell determinants.

Overlapping synthetic peptides corresponding to the sequence of full-length MOG were tested for EAE induction in C57BL/6 mice (table 1). MOG p111-130 induced EAE in a manner similar to p35-55. In contrast, although MOG p181-195 and p186-200 had induced T-cell proliferative responses, neither clinical (table 1) nor histologic (table e-1) signs of EAE were observed after immunization with any peptide doses tested (data not shown).

Identification of the encephalitogenic MOG T-cell determinant, p119-132. In general, $\mathrm{T}$ cells recognize linear peptide determinants containing 9-14 aa. ${ }^{18,19}$ Thus, we characterized the encephalitogenic region further by testing shorter overlapping peptides. MOG p116-130 elicited proliferation after immunization with MOG p111-130 (figure 1B) and was encephalitogenic (table 2), whereas MOG p111-125 did not stimulate proliferation or cause EAE.

The minimal encephalitogenic T-cell determinant within MOG p116-130 was identified using nested peptides truncated by individual residues from its $\mathrm{N}$-terminus or C-terminus. While MOG p119-130 stimulated proliferation (figure $1 \mathrm{C}$ ) and caused EAE (table 2), p120-130 did not stimulate proliferation or cause EAE, suggesting that the Phe at residue 119 is critical for recognition of this determinant. As the inability to stimulate proliferation with p120-130 could simply have reflected a requirement for length of this determinant, we immunized mice with MOG p120-131 and p120-132. These 2 peptides did not stimulate proliferation (figure e-1A) or cause EAE (table 2), confirming the importance of hydrophobic residue, Phe, at position 119 of this T-cell epitope. Peptide 119-128, which was the shortest peptide to stimulate proliferation (figure 1D), was also the smallest one to cause EAE (table 2). Peptide 119-130 induced clinical and histologic EAE as potently as p35-55. The addition of residues 131 and 132 to this sequence created peptides that had slightly greater stimulatory capacity. Increasing length at the C-terminus beyond residue 132 (e.g., p119-133) did not increase the stimulatory capacity (figure e-1A) or encephalitogenic potential (table 2). Collectively, these results indicated that $\mathrm{p} 119-132$ contains the complete encephalitogenic T-cell epitope of this region.

MOG p119-132-specific T cells are $\mathrm{CD}^{+}$and MHC II $\left(\mathrm{I}-\mathrm{A}^{\mathrm{b}}\right)$-restricted, produce proinflammatory $\mathrm{T}$ cells, and transfer EAE to naive recipient mice. In most EAE models, encephalitogenic myelin autoantigen-specific $\mathrm{T}$ cells are $\mathrm{CD}^{+}{ }^{+}$and MHC II-restricted. ${ }^{20}$ In this 
A

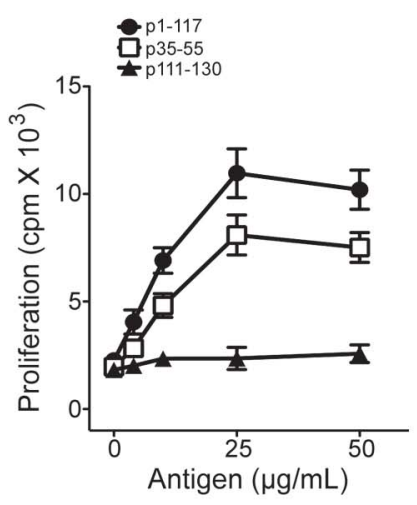

E MOG p119-132-specific lymphocytes
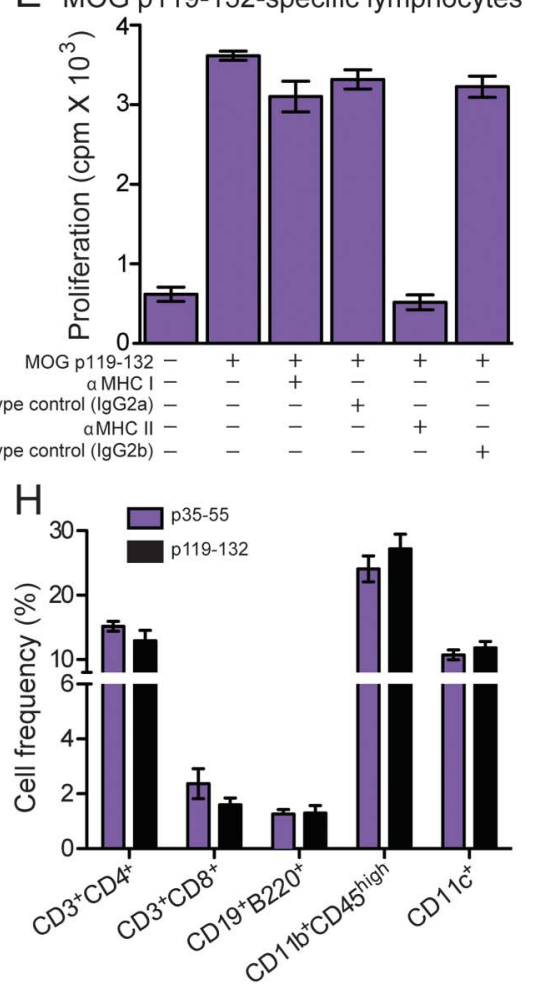

$\mathrm{B}$

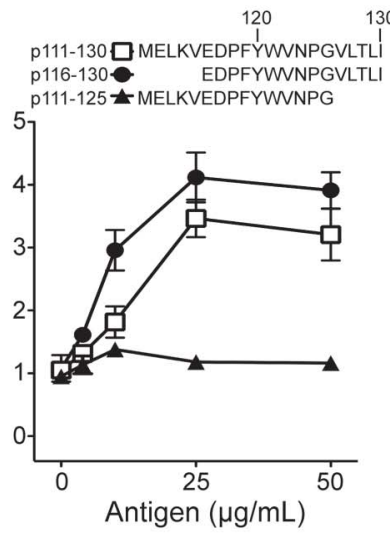

$\mathrm{F}$

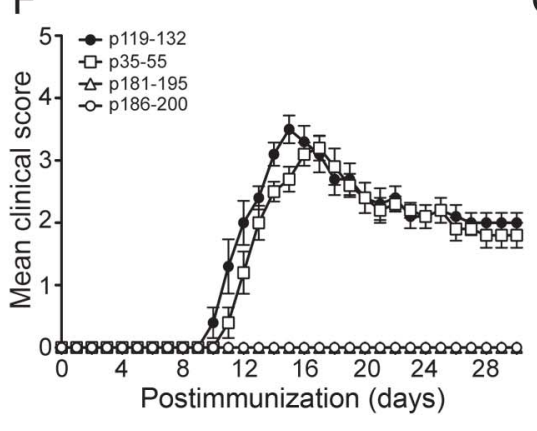

I

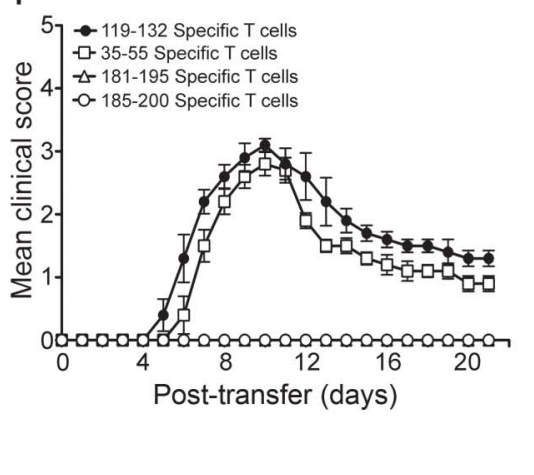

120 p116-130 EDPFYWNNPGVLTLI p117-130 DPFYWNNPGVLTH p117-130 DPFYWNPGVLTLI p118-130 PFYWNPGVLTLI p119-130 FYWVNPGVLTLI

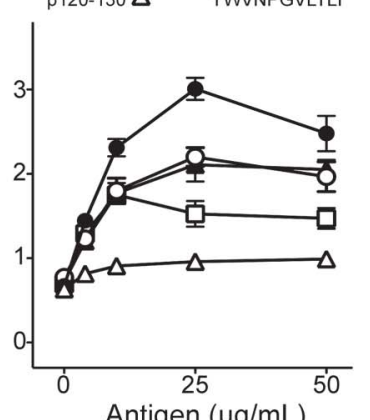

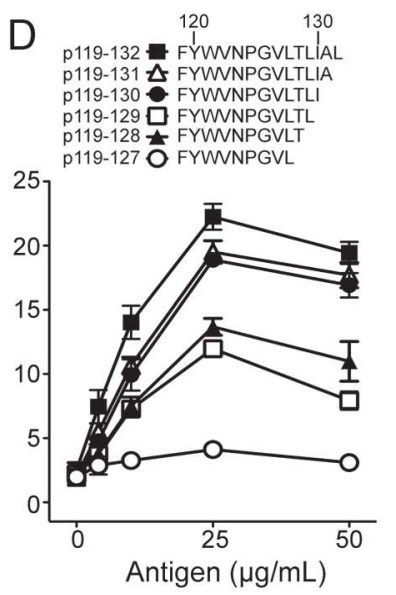

$\mathrm{G}$

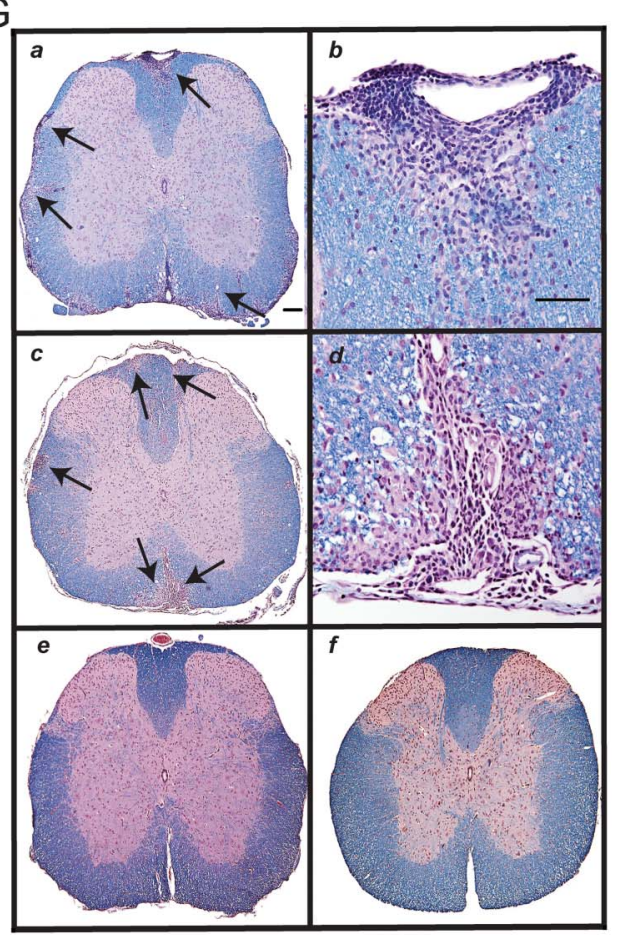

(A) Immunization with rMOG 1-117 elicited a recall proliferative response to $\mathrm{p} 35-55$ but not to $\mathrm{p} 111-130$. (B) Proliferation was detected to MOG $\mathrm{p} 116-130$ but not to $\mathrm{p} 111-125$ in mice immunized with $\mathrm{p} 111-130$. (C) Testing proliferative responses to truncated peptides after immunization with MOG p116-130 identified the core $\mathrm{N}$-terminal boundary, $\mathrm{F}^{119}$. (D) Recall proliferative responses to MOG p119-132 and truncated peptides after immunization with MOG p119-132 identified the core C-terminal boundary, $\mathrm{T}^{128}$. The proliferative response was maximal for $\mathrm{p} 119-132$. Lymph node cells were harvested 12 days after immunization. Results shown in panels A-D are representative of 3 separate experiments with 4 mice/group. (E) Mice were primed with MOG p119132. Lymph node cells were isolated on day 10 and restimulated with MOG p119-132 in the presence of anti-MHC class II (M5/114), anti-MHC class I (2814-8), or isotype control antibodies. Proliferation was evaluated after 72 hours by thymidine incorporation. (F, G) Mice were immunized with MOG p35-55, MOG p119-132, p181-195, and p186-200 for experimental autoimmune encephalomyelitis (EAE) induction. (F) EAE clinical course was similar after immunization with p35-55 and p119-132, but no signs of disease were observed with MOG p181-195 and p186-200. Data are representative of 5 separate experiments (5 mice/group) and represent mean clinical scores \pm SEM. (G) Histologic analysis was performed on mice 14 days after immunization. Mice immunized with p35-55 (a, b) and p119-132 (c, d) developed EAE lesions in spinal cord white matter (arrows in a and c). (b, d) Meningeal and parenchymal mononuclear cell inflammation and demyelination were observed at higher magnifications. No evidence of histologic disease was observed in spinal cords of mice immunized with MOG p181-195 (e) or p186-200 (f). Luxol fast blue-hematoxylin \& eosin; scale bars $100 \mu \mathrm{m}$ (a, c, e, and f), $50 \mu \mathrm{m}$ (b and d). (H) Mice were immunized with p35-55 or p119-132 and CNS-infiltrating cells were isolated 4 days after disease onset. Cells were stained with markers specific for $\mathrm{CD} 4^{+} \mathrm{T}$ cells, CD8 ${ }^{+}$T cells, B cells $\left(\mathrm{CD} 19^{+} \mathrm{B} 22 \mathrm{O}^{+}\right)$, monocytes $\left(\mathrm{CD} 11 \mathrm{~b}^{+}, \mathrm{CD} 45^{\text {high }}\right)$, and dendritic cells (CD11 $\left.\mathrm{c}^{+}\right)$. (I) Adoptive transfer EAE was induced by MOG p119-132-specific and p35-55-specific CD4+ ${ }^{+}$cells but not by p181-195-specific and p186-200-specific T cells. MOG epitope-specific $\mathrm{CD} 4^{+} \mathrm{T}$ cells were isolated from mice primed with individual MOG peptides and adoptively transferred into naïve recipient mice by intraperitoneal injection. Data shown represent mean clinical scores \pm SEM of 5 recipient mice/group. EAE incidence was $100 \%$ in recipients of MOG p119132-specific or p35-55-specific T cells. No clinical EAE was detected in recipient mice that received donor MOG p181-195-specific or p186-200-specific T cells. Results are representative of 3 independent experiments. MHC = major histocompatibility complex; MOG = myelin oligodendrocyte glycoprotein. 
Table 2 Identification of the minimal encephalitogenic sequence, p119-128, within the transmembrane region of myelin oligodendrocyte glycoprotein (MOG)

\begin{tabular}{|c|c|c|c|c|}
\hline \multicolumn{2}{|c|}{ MOG peptide } & \multirow[b]{2}{*}{$\begin{array}{l}\text { Disease } \\
\text { incidence }\end{array}$} & \multirow[b]{2}{*}{$\begin{array}{l}\text { Mean day of } \\
\text { disease onset }\end{array}$} & \multirow[b]{2}{*}{$\begin{array}{l}\text { Mean maximal } \\
\text { severity }^{\mathrm{a}}\end{array}$} \\
\hline Residue & Sequence & & & \\
\hline p35-55 & EVGWYRSPFSRVVHLY & $15 / 15$ & $11.2 \pm 0.3$ & $3.5 \pm 0.4$ \\
\hline p111-130 & MELKVEDPFYWVNPGVLTLI & $10 / 10$ & $12.7 \pm 0.4$ & $2.9 \pm 0.4$ \\
\hline $\mathrm{p} 111-125$ & MELKVEDPFYWVNPG & $0 / 10$ & - & - \\
\hline p116-130 & EDPFYWVNPGVLTLI & $10 / 10$ & $12.5 \pm 0.5$ & $3.5 \pm 0.3$ \\
\hline p117-130 & DPFYWVNPGVLTLI & $10 / 10$ & $12.5 \pm 0.2$ & $3.5 \pm 0.1$ \\
\hline p118-130 & PFYWVNPGVLTLI & $10 / 10$ & $11.7 \pm 0.4$ & $3.2 \pm 0.2$ \\
\hline p119-130 & FYWVNPGVLTLI & $15 / 15$ & $11.2 \pm 0.5$ & $3.6 \pm 0.3$ \\
\hline p120-130 & YWVNPGVLTLI & $0 / 10$ & - & - \\
\hline p120-131 & YWVNPGVLTLIA & $0 / 10$ & - & - \\
\hline p120-132 & YWVNPGVLTLIAL & $0 / 10$ & - & - \\
\hline p119-133 & FYWVNPGVLTLIALV & $4 / 5$ & $10.3 \pm 0.6$ & $3.0 \pm 0.3$ \\
\hline p119-132 & FYWVNPGVLTLIAL & $15 / 15$ & $10.2 \pm 0.7$ & $3.8 \pm 0.4$ \\
\hline p119-131 & FYWVNPGVLTLIA & $10 / 10$ & $11.0 \pm 0.4$ & $3.4 \pm 0.2$ \\
\hline p119-129 & FYWVNPGVLTL & $6 / 10$ & $12.0 \pm 0.5$ & $1.6 \pm 0.3$ \\
\hline p119-128 & FYWVNPGVLT & $7 / 10$ & $12.7 \pm 0.2$ & $1.7 \pm 0.2$ \\
\hline p119-127 & FYWVNPGVL & $0 / 10$ & - & - \\
\hline
\end{tabular}

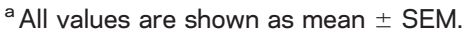

regard, T cells that proliferated to MOG p119-132 or p119-130 expressed CD4 but not CD8 molecules. A limited repertoire of TCR genes may be utilized for recognition of certain encephalitogenic myelin epitopes. ${ }^{21}$ For example, nearly $80 \%$ of MBP Ac11-specific $\mathrm{T}$ clones use the same TCR V $\beta$ gene. Although there was heterogeneity within the population of MOG p119-132-specific T cells as measured by TCR V $\beta$ usage, $40 \%$ of $\mathrm{CD}^{+} \mathrm{T}$ cells for this determinant utilized $\mathrm{V} \beta 8.3$, a $\mathrm{V} \beta$ that was rarely used by p35-55-specific $\mathrm{CD}^{+} \mathrm{T}$ cells (table e-2). Proliferation to MOG p119-132 was inhibited by anti-MHC II but not anti-MHC I antibodies (figure 1E), indicating that $\mathrm{T}$-cell recognition of MOG p119-132 is restricted by I-A ${ }^{\mathrm{b}}$ MHC II molecules. Besides inducing encephalitogenic responses in C57BL/6 mice, MOG peptides p119-130 and p119132 also caused EAE in C57BL/10 and 129/Sv, 2 other $\mathrm{H}-2^{\mathrm{b}}$ (I-A $\mathrm{A}^{\mathrm{b}}$ ) mouse strains (table 3). However, MOG p119-132, like p35-55, did not induce EAE in C57BL/6 $\mathrm{MOG}^{-1-}$ mice, ${ }^{22}$ indicating that $\mathrm{p} 119-132$ did not elicit encephalitogenic responses through crossreactivity with another CNS autoantigen (table e-3). In contrast to recombinant human MOG, which is a T-cell and B-cell dependent autoantigen and does not cause EAE in B-cell deficient (JHT) mice, ${ }^{15}$ p119-132 caused clinical and histologic EAE in JHT mice (data not shown). MOG p119-132 did not induce clinical or histologic EAE in NOD $\left(\mathrm{H}-2^{\mathrm{g}}{ }^{7}\right)$, Biozzi $\left(\mathrm{H}-2^{\mathrm{dq}}\right)$, or
PL/J (H-2 $\left.{ }^{u}\right)$ mouse strains that are susceptible to EAE induced by MOG $\mathrm{p} 35-55,2,23$ or in strains of other MHC $(H-2)$ haplotype genes that are susceptible to EAE induced by different myelin antigens. ${ }^{20}$

The clinical course of EAE induced by either p119132 or $\mathrm{p} 35-55$ in $\mathrm{C} 57 \mathrm{BL} / 6$ mice was similar at all equivalent peptide doses tested (figure $1 \mathrm{~F}$, table $\mathrm{e}-4$ ). Like MOG p35-55, p119-132 induced parenchymal and meningeal inflammation as well as demyelination. Optic neuritis was also observed. Composition and distribution of the CNS inflammatory lesions, as well as the frequencies of CNS-infiltrating $\mathrm{CD}^{+}$and $\mathrm{CD}^{+} \mathrm{T}$ cells, $\mathrm{B}$ cells, monocytes, and dendritic cells, were similar in EAE induced by p119-132 and p35-55 (figure 1, G and H).

Encephalitogenic myelin-specific $\mathrm{T}$ cells produce proinflammatory cytokines. ${ }^{3}$ Therefore, we examined various cytokines produced by $\mathrm{T}$ cells following immunization with MOG p119-132 and during acute EAE. T cells primed to p119-132 in complete Freund's adjuvant produced IFN- $\gamma$ and interleukin (IL)-17 in a manner that was similar to mice immunized with p35-55 (figure e-1B). Percentages of Th1 and Th17 cells in the periphery and in CNSinfiltrating cells were similar when EAE was induced by MOG p119-132 or p35-55 (figure 2A, figure $\mathrm{e}-1 \mathrm{~B})$. When used as donor cells for adoptive transfer, proinflammatory MOG p119-132-specific $\mathrm{T}$ cells induced $\mathrm{EAE}$ in naive recipient $\mathrm{C} 57 \mathrm{BL} / 6$ mice, 


\begin{tabular}{|c|c|c|c|c|c|c|c|}
\hline Table 3 & $9-132$ indu & $E A E$ in $\mathrm{H}-2^{b}$ mous & rains & & & & \\
\hline Strain & $\begin{array}{l}\text { MHC II } \\
\text { haplotype }\end{array}$ & Antigenic peptide & Incidence & $\begin{array}{l}\text { Mean day of } \\
\text { onset }^{\mathrm{a}}\end{array}$ & $\begin{array}{l}\text { Mean maximal } \\
\text { severity }^{\mathrm{a}}\end{array}$ & $\begin{array}{l}\text { Histologic } \\
\text { disease }^{b}\end{array}$ & $\begin{array}{l}\text { Recall proliferative } \\
\text { response }^{c}\end{array}$ \\
\hline \multirow[t]{2}{*}{ C57BL/6 } & $\mathrm{H}-2^{\mathrm{b}}$ & MOG p119-132 & $10 / 10$ & $11.5 \pm 0.3$ & $2.9 \pm 0.3$ & + & + \\
\hline & & MOG p35-55 & $5 / 5$ & $12.0 \pm 0.5$ & $2.6 \pm 0.4$ & + & + \\
\hline \multirow[t]{2}{*}{ Sv129 } & $\mathrm{H}-2^{\mathrm{b}}$ & MOG p119-132 & $10 / 10$ & $10.5 \pm 0.3$ & $3.0 \pm 0.2$ & + & + \\
\hline & & MOG p35-55 & $5 / 5$ & $11.5 \pm 0.5$ & $2.8 \pm 0.2$ & + & + \\
\hline \multirow[t]{2}{*}{ B10 } & $\mathrm{H}-2^{\mathrm{b}}$ & MOG p119-132 & $10 / 10$ & $10.0 \pm 0.5$ & $3.2 \pm 0.3$ & + & + \\
\hline & & MOG p35-55 & $5 / 5$ & $11.0 \pm 0.4$ & $2.9 \pm 0.2$ & + & + \\
\hline \multirow[t]{2}{*}{ BALB/c } & $H-2^{d}$ & MOG p119-132 & $0 / 5$ & - & - & - & - \\
\hline & & PLP p139-151 & $3 / 5$ & $17.0 \pm 0.7$ & $2.2 \pm 0.5$ & + & + \\
\hline \multirow[t]{2}{*}{ B10.A } & $\mathrm{H}-2^{\mathrm{k}}$ & MOG p119-132 & $0 / 10$ & - & - & - & - \\
\hline & & MBP Ac1-11 & $5 / 5$ & $21.0 \pm 0.5$ & $2.7 \pm 0.4$ & + & + \\
\hline \multirow[t]{2}{*}{$A / J$} & $\mathrm{H}-2^{\mathrm{k}}$ & MOG p119-132 & $0 / 10$ & - & - & - & - \\
\hline & & MBP Ac1-11 & $3 / 5$ & $20.3 \pm 0.5$ & $2.2 \pm 0.2$ & + & + \\
\hline \multirow[t]{2}{*}{ B10.PL } & $\mathrm{H}-2^{\mathrm{u}}$ & MOG p119-132 & $0 / 5$ & - & - & - & - \\
\hline & & MBP Ac1-11 & $3 / 5$ & $15.0 \pm 0.6$ & $2.0 \pm 0.3$ & + & + \\
\hline \multirow[t]{2}{*}{$\mathrm{PL} / \mathrm{J}$} & $\mathrm{H}-2^{\mathrm{u}}$ & MOG p119-132 & $0 / 10$ & - & - & - & - \\
\hline & & MBP Ac1-11 & $4 / 5$ & $18.0 \pm 0.4$ & $2.3 \pm 0.3$ & + & + \\
\hline \multirow[t]{2}{*}{ SJL/J } & $\mathrm{H}-2^{\mathrm{s}}$ & MOG p119-132 & $0 / 10$ & - & - & - & - \\
\hline & & PLP p139-151 & $5 / 5$ & $16.0 \pm 0.5$ & $2.6 \pm 0.2$ & + & + \\
\hline \multirow[t]{2}{*}{$(\mathrm{PL} / \mathrm{J} \times \mathrm{SJL} / \mathrm{J}) \mathrm{F}_{1}$} & $\mathrm{H}-2^{\mathrm{u} / \mathrm{s}}$ & MOG p119-132 & $0 / 5$ & - & - & - & - \\
\hline & & MBP Ac1-11 & $5 / 5$ & $13.2 \pm 0.2$ & $3.2 \pm 0.1$ & + & + \\
\hline \multirow[t]{2}{*}{ NOD } & $H-2^{97}$ & MOG p119-132 & $0 / 10$ & - & - & - & - \\
\hline & & MOG p35-55 & $5 / 5$ & $14.4 \pm 0.4$ & $2.0 \pm 0.2$ & + & + \\
\hline \multirow[t]{2}{*}{ Biozzi } & $\mathrm{H}-2^{\mathrm{dq} 1}$ & MOG p119-132 & $0 / 10$ & - & - & - & - \\
\hline & & MOG p35-55 & $7 / 7$ & $20.6 \pm 0.9$ & $3.6 \pm 0.5$ & + & + \\
\hline
\end{tabular}

Abbreviations: $\mathrm{EAE}=$ experimental autoimmune encephalomyelitis; $\mathrm{MBP}=$ myelin basic protein; $\mathrm{MHC}=$ major histocompatibility complex; $\mathrm{MOG}=$ myelin oligodendrocyte glycoprotein; PLP = proteolipid protein.

${ }^{a} \mathrm{EAE}$ results are shown as mean $\pm \mathrm{SEM}$.

${ }^{\mathrm{b}}$ Three mice per group were examined for CNS inflammation and demyelination.

${ }^{\mathrm{c}}$ Recall proliferative responses with a stimulation index $>2.5$ were considered positive. Each proliferation assay was set up on 5 mice and is representative of 2 independent experiments.

demonstrating the pathogenicity of those $\mathrm{T}$ cells (figure 1I). Incidence, onset, and severity of acute and chronic EAE were similar when induced by MOG p119-132-specific T cells or p35-55-specific $\mathrm{T}$ cells.

Of interest, donor $\mathrm{T}$ cells specific for p181-195 or p186-200 that produced proinflammatory cytokines did not induce clinical (figure 1I) or histologic (table 4) EAE in recipient WT mice. $\mathrm{RAG1}^{-1-}$ mice, which do not contain either mature $\mathrm{T}$ or $\mathrm{B}$ cells, are more susceptible to EAE induction by donor encephalitogenic T cells than WT recipient mice. $^{24,25}$ When using this sensitive EAE measure, MOG p186-200-specific T cells rarely caused clinical $(1 / 20$ mice tested) or histologic $(2 / 20$ mice tested) EAE. Donor T cells specific for p181-195 did not induce clinical or histologic signs of EAE (table 4), confirming that p181-195 is indeed a nonencephalitogenic MOG T-cell determinant. Notably, frequencies of IL- $17^{+}$, IFN- $\gamma^{+}$, and IL- $17^{+}$IFN- $\gamma^{+}$T cells were statistically lower after immunization with the nonencephalitogenic T-cell determinant MOG p181-195 (figure 2B).

p119-132 is an immunodominant $T$-cell epitope of native MOG. In general, multideterminant protein antigens, like native MOG, are processed by APC., ${ }^{6,15}$ By definition, immunodominant $\mathrm{T}$-cell epitopes are those that are recognized more frequently among all $\mathrm{T}$ cells responding to the naturally processed protein. ${ }^{26}$ Even though MOG p119-132 caused EAE as severe as MOG p35-55, it was possible that p119-132 represented a subdominant or cryptic determinant. Thus, we immunized mice with native MOG and examined recall to itself, p35-55, p119-132, p181-195, 


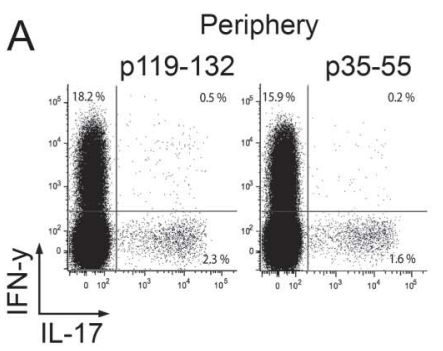

C

$$
\begin{aligned}
& \text { Immunization: } \\
& \text { Full-length MOG }
\end{aligned}
$$
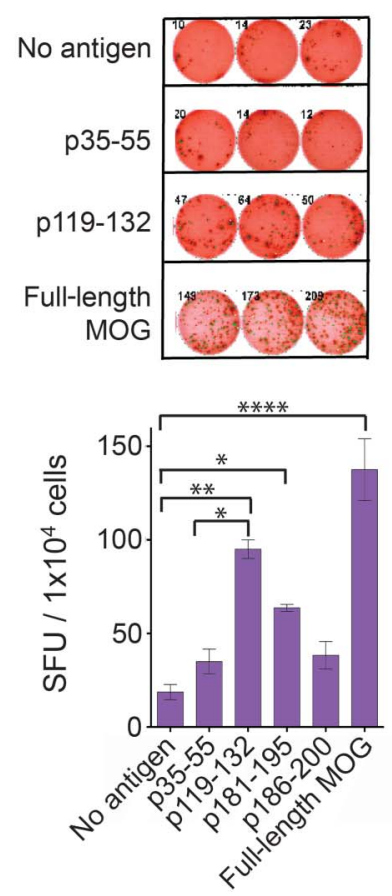

CNS

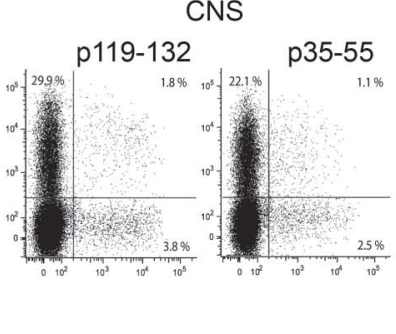

Immunization: rMOG 1-117
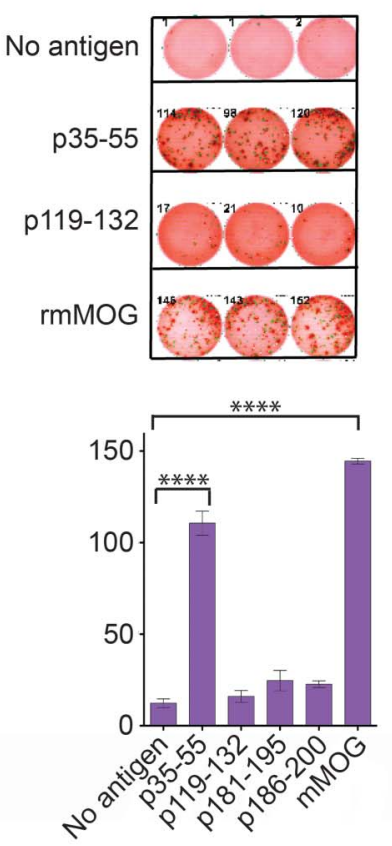

B
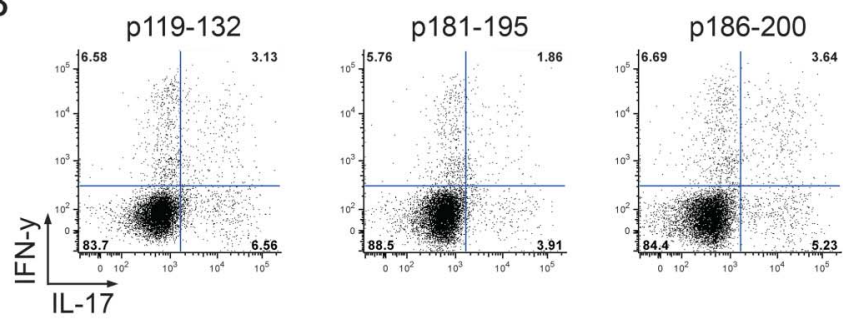

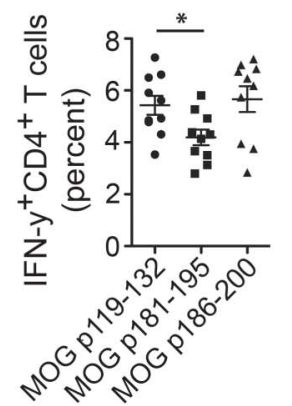

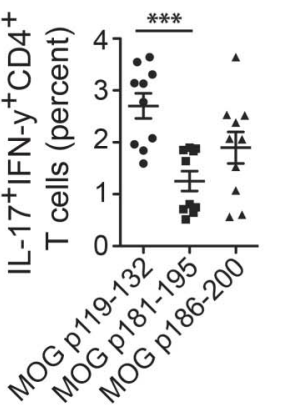

D

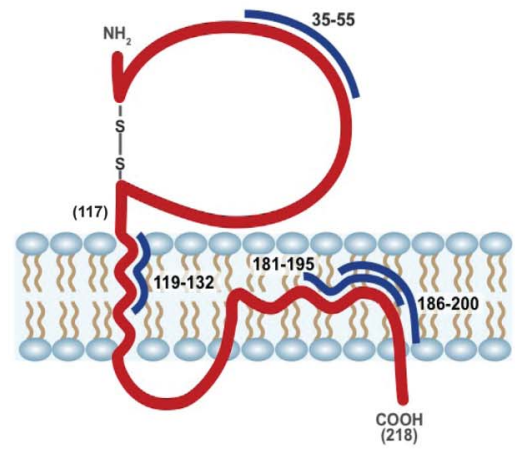

(A, B) Mice were immunized with myelin oligodendrocyte glycoprotein (MOG) p35-55, p119-132, p181-195, and p186-200. (A) Fourteen days after immunization with p35-55 and p119-132, spleen cells and CNS-infiltrating cells were isolated and analyzed for interleukin (IL)-17 and interferon (IFN)- $\gamma$ production by intracellular staining after stimulation with phorbol 12-myristate 13-acetate (PMA)/ionomycin for 5 hours. Results are representative of 2 experiments that tested 4 individual mice for each peptide immunization. (B) Ten days after immunization with p119-132, p181-195, and p185-200, spleen cells were isolated and analyzed for IL-17 and IFN- $\gamma$ production by intracellular staining after stimulation with PMA/ionomycin for 5 hours. Data summarize 2 experiments that tested 5 individual mice for each peptide immunization. (C) Frequencies of MOG peptide-specific IFN- $\gamma$-secreting cells were determined by ELISPOT as described in the methods. Lymph node cells from mice immunized with full-length MOG (left panel) or the extracellular domain of MOG (rMOG 1-117) (right panel) were cultured with the respective antigen used for immunization. Quantification of MOG peptide-specific T cells was performed at the time of restimulation with MOG peptides $(25 \mu \mathrm{g} / \mathrm{mL}$ ). Results are representative of 3 separate experiments (3 mice/group). (D) Schematic anatomic localization of T-cell epitopes within full-length (218 amino acid) mouse MOG (indicated in red). ${ }^{41}$ Amino acid 117 , the last residue of extracellular domain, is indicated. T-cell determinants are highlighted in blue.

and p186-200. ELISPOT analysis of IFN- $\boldsymbol{\gamma}$-secreting cells, a highly sensitive measure to examine the repertoire of antigen-specific $\mathrm{T}$ cells, ${ }^{27,28}$ was used to quantitate the frequency of MOG-specific T cells. Of responses to the peptide determinants, the frequency of IFN- $\gamma$-secreting T cells was highest for MOG p119132 (figure 2C) and was significantly greater than for MOG p35-55. These results indicated that $\mathrm{p} 35-55$ is not the immunodominant T-cell epitope of MOG. In parallel, we examined the response to these peptides after immunization with the extracellular MOG domain. Immunization with MOG 1-117 elicited a robust response to MOG p35-55 (figure 2C, left panel) but not to the novel determinants located in the transmembrane and cytoplasmic domains (figure 2C, right panel). Similar results were obtained when testing a different concentration of MOG peptides in recall to immunization with full-length MOG or rMOG (figure e-1C).

DISCUSSION MOG, a minor component of myelin protein, was first recognized as a CNS autoantigen in 


\begin{tabular}{|c|c|c|c|c|c|c|}
\hline \multirow[b]{3}{*}{ MOG peptide } & \multicolumn{6}{|c|}{$\begin{array}{l}\text { Development of experimental autoimmune encephalomyelitis (EAE) in recipient mice after adoptive } \\
\text { transfer of myelin oligodendrocyte glycoprotein (MOG) peptide-specific T cells }\end{array}$} \\
\hline & \multicolumn{3}{|l|}{ Clinical EAE } & \multicolumn{3}{|c|}{ No. of inflammatory foci } \\
\hline & Incidence, \% & $\begin{array}{l}\text { Mean day } \\
\text { of onset }^{\mathrm{a}}\end{array}$ & $\begin{array}{l}\text { Mean score at } \\
\text { peak of disease }^{a}\end{array}$ & Meninges $^{a}$ & Parenchyma $^{a}$ & Total \\
\hline \multicolumn{7}{|l|}{ Wild-type } \\
\hline $119-132$ & $100(15 / 15)$ & $6.5 \pm 0.7$ & $3.2 \pm 0.2$ & $113 \pm 7.7$ & $138 \pm 9.9$ & $244.3 \pm 13.2$ \\
\hline $35-55$ & $100(15 / 15)$ & $7.4 \pm 0.5$ & $2.8 \pm 0.5$ & $100.3 \pm 17.0$ & $85 \pm 7.0$ & $185.3 \pm 22.3$ \\
\hline 181-195 & $0(0 / 15)$ & 0 & 0 & 0 & 0 & 0 \\
\hline $186-200$ & $0(0 / 15)$ & 0 & 0 & 0 & 0 & 0 \\
\hline \multicolumn{7}{|l|}{ RAG1-I- } \\
\hline $119-132$ & $100(14 / 14)$ & $18.5 \pm 0.9$ & $2.75 \pm 0.3$ & $121 \pm 19.3$ & $132 \pm 22.8$ & $255.3 \pm 39.2$ \\
\hline $35-55$ & $100(5 / 5)$ & $16.8 \pm 1.2$ & $2.4 \pm 0.4$ & $83.2 \pm 17.5$ & $120.2 \pm 22.7$ & $203.4 \pm 37.8$ \\
\hline 181-195 & $0(0 / 15)$ & 0 & 0 & 0 & 0 & 0 \\
\hline $186-200$ & $5(1 / 20)$ & $19^{b}$ & $3^{b}$ & $36.5 \pm 2.84^{c}$ & $41 \pm 1.89^{c}$ & $77.5 \pm 4.74^{c}$ \\
\hline
\end{tabular}

Results are representative of 3 independent experiments ( 4 mice/group/experiment).

${ }^{a}$ Results represent mean \pm SEM. Donor mice were primed by being injected subcutaneously with $50 \mu \mathrm{g} / \mathrm{mouse}$ of relevant MOG peptide.

${ }^{\mathrm{b}}$ Results represent actual values (i.e., not mean).

${ }^{\mathrm{c}}$ Results represent mean \pm SEM of the 2 mice with inflammatory loci (i.e., 18/20 mice examined did not have detectable CNS inflammatory loci).

1993. ${ }^{7}$ Since then, most studies evaluating immune responses to MOG have focused on its extracellular Ig-like domain. ${ }^{11,29-31}$ In C57BL/6 mice, the encephalitogenic T-cell determinant of the extracellular MOG domain, rMOG, was mapped to residues 35-55. ${ }^{32}$ Subsequently, p35-55 has emerged as a widely used encephalitogenic myelin antigen for EAE investigations. ${ }^{33,34}$ Although separate encephalitogenic determinants of rMOG have been identified in other mouse strains with different $\mathrm{H}-2$ haplotypes, ${ }^{12,29}$ in $\mathrm{C} 57 \mathrm{BL} / 6$ mice $\left(\mathrm{H}-2^{\mathrm{b}}\right)$ p35-55 is the widely recognized encephalitogenic $\mathrm{T}$-cell epitope of MOG. ${ }^{32}$ In contrast, MBP and PLP, 2 other CNS autoantigens, contain multiple pathogenic T-cell epitopes in $\mathrm{H}-2^{\mathrm{u}}$ as well as $\mathrm{H}-2^{\mathrm{s}}$ strains. ${ }^{35,36}$ Because the extracellular domain represents only $54 \%$ of the MOG aa sequence and earlier studies suggested intact MOG protein might contain additional T-cell determinants, we investigated this possibility. We discovered 3 discrete T-cell determinants, one located within the transmembrane domain and 2 within the cytoplasmic domain (figure 2D). ${ }^{13} \mathrm{~A}$ more recent report also described $\mathrm{T}$-cell determinants within these 2 regions in C57BL/6 mice. ${ }^{8}$ Here, we demonstrate the transmembrane MOG determinant, p119-132, caused EAE as potently as MOG $35-55$ in $3 \mathrm{H}-2^{\mathrm{b}}$ strains. By examining individual responses to MOG p35-55, p119132, and the 2 epitopes within the cytoplasmic domain following immunization with intact full-length MOG, we were capable of evaluating the physiologic T-cell repertoire to MOG determinants generated in vivo. To our surprise, a higher frequency of MOG proteinspecific $\mathrm{T}$ cells recognized p119-132 than p35-55.
Thus, p35-55 is not the immunodominant encephalitogenic T-cell determinant of native MOG. Whether the immunodominance of p119-132 reflects greater affinity for $\mathrm{I}-\mathrm{A}^{\mathrm{b}}$ than other MOG determinants or is due to distinct processing requirements is not clear. ${ }^{6}$ Recognizing that MOG contains multiple pathogenic T-cell epitopes in this widely studied model and that p119-132 is one of the immunodominant T-cell epitopes will permit evaluation of potential changes in the MOG-specific T-cell repertoire during EAE pathogenesis. Of interest, it is recognized that the pathogenic humoral response targets the extracellular Ig MOG domain, which contains the aa sequence 35-55 recognized by pathogenic $\mathrm{T}$ cells. Identification of the encephalitogenic MOG transmembrane T-cell epitope, p119-132, should permit examination of whether T cells targeting this distinct anatomic domain participate in T-B collaboration and the MOG-specific humoral response in a different manner than when both $\mathrm{T}$ and $\mathrm{B}$ cells target the same region.

Many mouse strains, representing different haplotypes, are susceptible to EAE induced by various myelin proteins. ${ }^{20}$ MOG p35-55 induces EAE in $\mathrm{H}-2^{\mathrm{b}}$ strains as well as in mice that express $\mathrm{H}-2^{\mathrm{u}}$ (e.g., $\mathrm{PL} / \mathrm{J}), \mathrm{H}-2^{\mathrm{g} 7}$ (e.g., NOD), and $\mathrm{H}-2^{\mathrm{dq} 1}$ (e.g., Biozzi) haplotypes. $^{2,23}$ It is interesting that although we evaluated EAE induction by MOG p119-132 in all of those strains, T-cell proliferative responses, CNS inflammation, and clinical EAE were induced only in $\mathrm{H}-2^{\mathrm{b}}$ strains. These observations suggest that residues in MOG p119-132 and p35-55 utilize distinct agretopes and do not contact the MHC II (I-A $\left.{ }^{\mathrm{b}}\right)$ peptide-binding 
groove in precisely the same manner. The lack of immunogenicity is unlikely to be due to potential differences in TCR repertoire, as all of these particular strains contain intact TCR $\alpha$ and $\beta$ gene repertoires. In future studies, it may be important to define the physical MHC II binding characteristics of p119-132.

In 1985 it was demonstrated for the first time that autoantigen-specific T-cell clones could mediate autoimmune disease. ${ }^{37}$ At that time we also showed that only $\mathrm{T}$-cell clones that recognized shared determinants of mouse (self) MBP, but not foreign determinants of heterologous (e.g., human or guinea pig) MBP alone, were capable of causing CNS inflammation and clinical disease in recipient mice, establishing the importance of self-nonself discrimination in CNS autoimmunity ${ }^{37,38}$ Since that time, it was observed that like dominant T-cell determinants of CNS autoantigens, ${ }^{19}$ peptides corresponding to subdominant or cryptic T-cell determinants of self-myelin antigens in general also cause EAE, sometimes as potently as the immunodominant epitope. ${ }^{35}$ In contrast to T-cell recognition of autoantigens, humoral responses to self-antigens can be pathogenic or nonpathogenic. ${ }^{39,40}$ It is interesting that here we did not observe clinical EAE or histologic evidence of CNS inflammation either by direct immunization with mouse MOG p181-195 or p186-200, or by adoptive transfer of proinflammatory-polarized $\mathrm{T}$ cells to these determinants, even when testing excessively large amounts of peptides or numbers of T cells. Further, T cells specific for MOG p181-195 did not induce clinical or histologic evidence of EAE even when transferred into T- and B-cell-deficient RAG $1^{-1-}$ mice, which are more susceptible to EAE than WT recipient mice. A lower frequency of proinflammatory $\mathrm{T}$ cells was elicited by immunization with p181-195 than p119-132, which could be one of the factors contributing to its inability to cause EAE. Although "absence of proof is not proof of absence," with these experimental paradigms, we have now identified a stimulatory T-cell epitope of a self CNS autoantigen that is not encephalitogenic. Thus, like for antibody responses, pathogenic and nonpathogenic T-cell determinants of CNS autoantigens may exist. Identification of a nonpathogenic determinant of MOG should now permit investigators to test whether therapeutics targeting a nonencephalitogenic T-cell epitope of this multideterminant autoantigen can regulate pathogenic responses. In our accompanying report, we demonstrated that $\mathrm{T}$ cells from patients with MS also recognized the corresponding novel determinants within transmembrane and cytoplasmic domains of human MOG. ${ }^{14}$ Both pathogenic and nonpathogenic T-cell epitopes may also exist within CNS autoantigens in humans.

\section{AUTHOR CONTRIBUTIONS}

A.S., S.G.G., M.V.-D., and S.S.Z. designed the study, analyzed data, and wrote the paper. A.S., S.G.G., M.V.-D., M.S.W., T.P., N.M., and U.S.T. performed the experiments. J.C.P. and N.J. assisted in the experiments. P.A.N., S.E.F., and A.J.S. gave conceptual advice and discussed the results. R.A.S. performed the histologic analysis. T.F. and C.C.A.B. contributed new reagents. S.S.Z. supervised the study.

\section{ACKNOWLEDGMENT}

The authors acknowledge the expertise of Saisha Nalawade, MS in analyzing the ELISPOT assays.

\section{STUDY FUNDING}

M.V.-D. and U.S.-T. are postdoctoral fellows of the NMSS. T.F and N.L. are supported by grants G12MD007591 from the NIH and RG3701 from the NMSS. S.S.Z. was supported by Boehringer Ingelheim, Guthy Jackson Charitable Foundation, Maisin Foundation, NIH (RO1 AI073737 and RO1 NS063008), and National Multiple Sclerosis Society (RG 4124). C.C.A.B. was supported by grants from the Baker Foundation, the Victoria/CIRM Joint Project (RMI-01739), the Medical Research Council of Australia, and the NMSS (RG3844A2/1).

\section{DISCLOSURE}

A.S., S.G.G., M.S.W., N.M., N.J., P.A.N. and R.A.S. report no disclosures. M.V.-D. received a travel grant from Teva Pharmaceuticals and research support from NMSS. T.P. is an employee of Momenta Pharmaceuticals. J.C.P. is an employee of Pfizer, Inc. U.S.-T. is an employee of Silence Therapeutics GmbH. S.E.F. and A.J.S. are employees of Boehringer-Ingelheim. T.F. is on the editorial board for Immunotherapy, is an associate editor for Plos One, is an editor for Frontiers Multiple Sclerosis and Neuroimmunology, is senior editor for the Journal of Immunology and Expert Review of Clinical Immunology, and receives research support from the National MS Society. C.C.A.B. is on the editorial board for Future Neurology and was a guest editor for Inflammation and Regeneration; and receives research support from NHMRC of Australia, the Victorian Government, and Eva and Les Erdi AUSiMED Fellowship in Neurological Diseases. S.S.Z. has served on the Data Safety Monitoring Boards for MS trials conducted by BioMS, Teva Pharmaceuticals Inc, Opexa Therapeutics, and Eli Lilly and Co; is an associate editor for Neurology: Neuroimmunology or Neuroinflammation and the Journal of the Neurological Sciences; has received honoraria from Eli Lilly and Co, Biogen Idec, Teva Neuroscience, and EMD Serono; has consulted for Biogen Idec, Teva Neuroscience, EMD Serono, Genzyme, and Novartis; is on the speakers' bureaus for Advanced Health Media and Biogen; and has received research support from Boehringer Ingelheim, NIH, NMSS, and Guthy Jackson Charitable Foundation. Go to Neurology.org/nn for full disclosures.

Received April 30, 2014. Accepted in final form June 26, 2014.

\section{REFERENCES}

1. Berger T, Rubner P, Schautzer F, et al. Antimyelin antibodies as a predictor of clinically definite multiple sclerosis after a first demyelinating event. N Engl J Med 2003;349:139-145.

2. Bernard CC, Johns TG, Slavin A, et al. Myelin oligodendrocyte glycoprotein: a novel candidate autoantigen in multiple sclerosis. J Molecular Med 1997;75:77-88.

3. Bettelli E, Pagany M, Weiner HL, Linington C, Sobel RA, Kuchroo VK. Myelin oligodendrocyte glycoprotein-specific $\mathrm{T}$ cell receptor transgenic mice develop spontaneous autoimmune optic neuritis. J Exp Med 2003;197:1073-1081.

4. Elong Ngono A, Pettre S, Salou M, et al. Frequency of circulating autoreactive $\mathrm{T}$ cells committed to myelin determinants in relapsing-remitting multiple sclerosis patients. Clin Immunol 2012;144:117-126.

5. Pham-Dinh D, Mattei MG, Nussbaum JL, et al. Myelin/ oligodendrocyte glycoprotein is a member of a subset of the immunoglobulin superfamily encoded within the major 
histocompatibility complex. Proc Natl Acad Sci U S A 1993; 90:7990-7994.

6. Slavin AJ, Soos JM, Stuve O, et al. Requirement for endocytic antigen processing and influence of invariant chain and $\mathrm{H}-2 \mathrm{M}$ deficiencies in CNS autoimmunity. J Clin Invest 2001;108:1133-1139.

7. Kerlero de Rosbo N, Milo R, Lees MB, Burger D, Bernard CC, Ben-Nun A. Reactivity to myelin antigens in multiple sclerosis. Peripheral blood lymphocytes respond predominantly to myelin oligodendrocyte glycoprotein. J Clin Invest 1993;92:2602-2608.

8. Delarasse C, Smith P, Baker D, Amor S. Novel pathogenic epitopes of myelin oligodendrocyte glycoprotein induce experimental autoimmune encephalomyelitis in C57BL/6 mice. Immunology 2013;140:456-464.

9. Linington C, Berger T, Perry L, et al. T cells specific for the myelin oligodendrocyte glycoprotein mediate an unusual autoimmune inflammatory response in the central nervous system. Eur J Immunol 1993;23:1364-1372.

10. Adelmann M, Wood J, Benzel I, et al. The N-terminal domain of the myelin oligodendrocyte glycoprotein (MOG) induces acute demyelinating experimental autoimmune encephalomyelitis in the Lewis rat. J Neuroimmunol 1995;63:17-27.

11. Kerlero de Rosbo N, Hoffman M, Mendel I, et al. Predominance of the autoimmune response to myelin oligodendrocyte glycoprotein (MOG) in multiple sclerosis: reactivity to the extracellular domain of MOG is directed against three main regions. Eur J Immunol 1997;27: 3059-3069.

12. Abdul-Majid KB, Jirholt J, Stadelmann C, et al. Screening of several $\mathrm{H}-2$ congenic mouse strains identified $\mathrm{H}-2$ (q) mice as highly susceptible to MOG-induced EAE with minimal adjuvant requirement. J Neuroimmunol 2000;111:23-33.

13. Gupta S, Shetty A, Weber M, et al. Novel T cell epitope 119-132 located within the transmembrane domain of myelin oligodendrocyte glycoprotein is the immunodominant encephalitogenic determinant. Mult Scler J 2011;17 (10 suppl):S327.

14. Varrin-Doyer M, Shetty A, Spencer CM, et al. MOG transmembrane and cytoplasmic domains contain highly stimulatory T-cell epitopes in MS. Neurol Neuroimmunol Neuroinflamm 2014;1:e20; doi: 10.1212/NXI.0000000000000020.

15. Molnarfi N, Schulze-Topphoff U, Weber MS, et al. MHC class II-dependent B cell APC function is required for induction of CNS autoimmunity independent of myelin-specific antibodies. J Exp Med 2013;210:29212937.

16. Linares D, Mana P, Goodyear M, et al. The magnitude and encephalogenic potential of autoimmune response to MOG is enhanced in MOG deficient mice. J Autoimmun 2003;21:339-351.

17. Kroepfl JF, Viise LR, Charron AJ, Linington C, Gardinier MV. Investigation of myelin/oligodendrocyte glycoprotein membrane topology. J Neurochem 1996; 67:2219-2222.

18. Garcia KC, Degano M, Stanfield RL, et al. An alphabeta T cell receptor structure at $2.5 \mathrm{~A}$ and its orientation in the TCR-MHC complex. Science 1996;274:209-219.

19. Zamvil SS, Mitchell DJ, Moore AC, Kitamura K, Steinman L, Rothbard JB. T-cell epitope of the autoantigen myelin basic protein that induces encephalomyelitis. Nature 1986;324:258-260.
20. Zamvil SS, Steinman L. The T lymphocyte in experimental allergic encephalomyelitis. Annu Rev Immunol 1990;8: 579-621.

21. Zamvil SS, Mitchell DJ, Lee NE, et al. Predominant expression of a $\mathrm{T}$ cell receptor $\mathrm{V}$ beta gene subfamily in autoimmune encephalomyelitis. J Exp Med 1988;167: 1586-1596.

22. Krishnamoorthy G, Saxena A, Mars LT, et al. Myelinspecific $\mathrm{T}$ cells also recognize neuronal autoantigen in a transgenic mouse model of multiple sclerosis. Nat Med 2009; 15:626-632.

23. Kerlero de Rosbo N, Mendel I, Ben-Nun A. Chronic relapsing experimental autoimmune encephalomyelitis with a delayed onset and an atypical clinical course, induced in PL/J mice by myelin oligodendrocyte glycoprotein (MOG)-derived peptide: preliminary analysis of MOG T cell epitopes. Eur J Immunol 1995;25:985-993.

24. Mombaerts P, Iacomini J, Johnson RS, Herrup K, Tonegawa S, Papaioannou VE. RAG-1-deficient mice have no mature B and T lymphocytes. Cell 1992;68: 869-877.

25. Lafaille JJ, Nagashima K, Katsuki M, Tonegawa S. High incidence of spontaneous autoimmune encephalomyelitis in immunodeficient anti-myelin basic protein $\mathrm{T}$ cell receptor transgenic mice. Cell 1994;78:399-408.

26. Sercarz EE, Lehmann PV, Ametani A, Benichou G, Miller A, Moudgil K. Dominance and crypticity of T cell antigenic determinants. Annu Rev Immunol 1993;11: 729-766.

27. Gross DM, Forsthuber T, Tary-Lehmann M, et al. Identification of LFA-1 as a candidate autoantigen in treatment-resistant Lyme arthritis. Science 1998;281: 703-706.

28. Goulder PJ, Tang Y, Brander C, et al. Functionally inert HIV-specific cytotoxic T lymphocytes do not play a major role in chronically infected adults and children. J Exp Med 2000;192:1819-1832.

29. Amor S, Groome N, Linington C, et al. Identification of epitopes of myelin oligodendrocyte glycoprotein for the induction of experimental allergic encephalomyelitis in SJL and Biozzi AB/H mice. J Immunol 1994;153:43494356.

30. Van der Aa A, Hellings N, Bernard CC, Raus J, Stinissen P. Functional properties of myelin oligodendrocyte glycoprotein-reactive $\mathrm{T}$ cells in multiple sclerosis patients and controls. J Neuroimmunol 2003;137: 164-176.

31. Hellings N, Baree M, Verhoeven C, et al. T-cell reactivity to multiple myelin antigens in multiple sclerosis patients and healthy controls. J Neurosci Res 2001;63:290-302.

32. Mendel I, Kerlero de Rosbo N, Ben-Nun A. A myelin oligodendrocyte glycoprotein peptide induces typical chronic experimental autoimmune encephalomyelitis in $\mathrm{H}-2 \mathrm{~b}$ mice: fine specificity and $\mathrm{T}$ cell receptor $\mathrm{V}$ beta expression of encephalitogenic $\mathrm{T}$ cells. Eur J Immunol 1995;25:1951-1959.

33. Liu J, Marino MW, Wong G, et al. TNF is a potent antiinflammatory cytokine in autoimmune-mediated demyelination. Nat Med 1998;4:78-83.

34. Greter M, Heppner FL, Lemos MP, et al. Dendritic cells permit immune invasion of the CNS in an animal model of multiple sclerosis. Nat Med 2005;11:328-334.

35. Zamvil SS, Mitchell DJ, Powell MB, Sakai K, Rothbard JB, Steinman L. Multiple discrete 
encephalitogenic epitopes of the autoantigen myelin basic protein include a determinant for I-E class II-restricted T cells. J Exp Med 1988;168:1181-1186.

36. Seamons A, Sutton J, Bai D, et al. Competition between two MHC binding registers in a single peptide processed from myelin basic protein influences tolerance and susceptibility to autoimmunity. J Exp Med 2003;197:1391-1397.

37. Zamvil S, Nelson P, Trotter J, et al. T-cell clones specific for myelin basic protein induce chronic relapsing paralysis and demyelination. Nature 1985;317:355-358.

38. Zamvil SS, Nelson PA, Mitchell DJ, Knobler RL, Fritz RB, Steinman L. Encephalitogenic T cell clones specific for myelin basic protein. An unusual bias in antigen recognition. J Exp Med 1985;162:2107-2124.

39. Marta CB, Oliver AR, Sweet RA, Pfeiffer SE, Ruddle NH. Pathogenic myelin oligodendrocyte glycoprotein antibodies recognize glycosylated epitopes and perturb oligodendrocyte physiology. Proc Natl Acad Sci U S A 2005;102: 13992-13997.

40. Karim AR, Jacob S. Immunological markers in neurological disorders. Ann Clin Biochem 2012;49:29-43.

41. della Gaspera B, Pham-Dinh D, Roussel G, Nussbaum JL, Dautigny A. Membrane topology of the myelin/oligodendrocyte glycoprotein. Eur J Biochem 1998;258:478-484. 


\title{
Neurology \\ Neuroimmunology \& Neuroinflammation
}

\author{
Immunodominant T-cell epitopes of MOG reside in its transmembrane and \\ cytoplasmic domains in EAE \\ Aparna Shetty, Sheena G. Gupta, Michel Varrin-Doyer, et al. \\ Neurol Neuroimmunol Neuroinflamm 2014;1; \\ DOI 10.1212/NXI.0000000000000022
}

This information is current as of August 14, 2014

\section{Updated Information \& \\ Services \\ Supplementary Material \\ References \\ Citations \\ Subspecialty Collections}

Permissions \& Licensing

Reprints including high resolution figures, can be found at:

http://nn.neurology.org/content/1/2/e22.full.html

Supplementary material can be found at:

http://nn.neurology.org/content/suppl/2014/08/16/1.2.e22.DC1

This article cites 41 articles, 12 of which you can access for free at: http://nn.neurology.org/content/1/2/e22.full.html\#\#ref-list-1

This article has been cited by 2 HighWire-hosted articles: http://nn.neurology.org/content/1/2/e22.full.html\#\#otherarticles

This article, along with others on similar topics, appears in the following collection(s):

Autoimmune diseases

http://nn.neurology.org//cgi/collection/autoimmune_diseases

Multiple sclerosis

http://nn.neurology.org//cgi/collection/multiple_sclerosis

Information about reproducing this article in parts (figures,tables) or in its entirety can be found online at:

http://nn.neurology.org/misc/about.xhtml\#permissions

Information about ordering reprints can be found online:

http://nn.neurology.org/misc/addir.xhtml\#reprintsus

Neurol Neuroimmunol Neuroinflamm is an official journal of the American Academy of Neurology.

Published since April 2014, it is an open-access, online-only, continuous publication journal. Copyright $\odot$ 2014 American Academy of Neurology. All rights reserved. Online ISSN: 2332-7812.

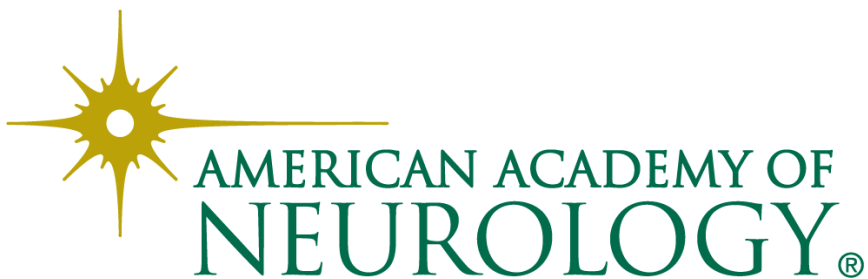

